\title{
UNAS BREVES NOTAS ACERCA DE LA PERSONA Y LA FILOSOFÍA DEL DERECHO DE JESÚS GONZÁLEZ AMUCHASTEGUI
}

\author{
Ernesto Garzón Valdés \\ Universidad de Mainz
}

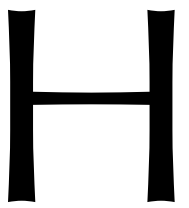

ace exactamente cinco años Jesús GONZÁLEZ AMUCHASTEGUI me pidió que escribiera el prólogo de su libro Autonomía, dignidad y ciudadanía. A pesar de que me considero poco apto para este tipo de escritos pues pienso que siempre se corre el peligro de caer en la alabanza fácil o en la reiteración inútil, acepté complacido esta invitación. Lo hice básicamente por dos motivos: primero, porque algo había ya leido de esta obra y llegado al convencimiento de que era un trabajo importante, que abría nuevas perspectivas para el tratamiento de temas tan manidos y escurridizos como son los de la dignidad y la autonomía humanas. Yo mismo había incursionado en este campo y sabía cuán difícil era escribir algo que pudiera aportar algún enfoque interesante o provocar una discusión relevante. Desde el punto de vista intelectual y profesional, pensé que valía la pena someter a crítica y análisis algunas de las tesis sostenidas por Jesús, tales como la versión historicista de los derechos humanos, la posible organización de un orden internacional justo y la relevancia moral de la dignidad humana. La segunda razón era el saber que compartía con él una concepción del quehacer intelectual que fundamentalmente consiste en procurar vincular con la mayor honestidad posible lo que uno profesionalmente piensa y la forma cómo uno se comporta en el ambiente social que nos ha tocado para suerte o desgracia vivir. En aquel prólogo - y también en diversas ocasiones académicas - polemicé con Jesús analizando argumentos y proponiendo soluciones que me parecían aceptablemente plausibles. No es mi propósito discutir ahora algunas ideas centrales de su pensamiento, sino más bien subrayar acuerdos y coincidencias. Ello puede servir a quienes lo conocimos personalmente como refuerzo de la memoria y a quienes no tuvieron esa oportunidad, como ejemplo de lo que puede y debe ser la vida y la obra de un jurista que, como ciudadano activo, no practica el aislamiento intelectual sino que procura vincular esencialmente lo que se sabe y la forma de cómo ha de vivirse lo que se sabe.

Hay tres acuerdos o coincidencias que quisiera subrayar aquí: 1. La relación entre la filosofía y la teoría del Derecho, por una parte, y la filosofía y la teoría de la política, por otra. 2. La autonomía del discurso moral en materia de derechos humanos y 3. La relevancia de la constitucionalización de los derechos humanos. 


\section{La relación entre la filosofía y la teoría del derecho, por una parte, y la filosofía y la teoría de la política, por otra}

En 1981, Norman P. BARRY había recordado la importancia que tenían para la filosofía y la teoría de la política los conceptos elaborados por la teoría y la filosofía del derecho ${ }^{1}$. Años más tarde, al estudiar el problema de la estabilidad de los sistemas políticos, utilicé la regla de reconocimiento hartiana como criterio de identidad y recurrí a estudios de politólogos y sociólogos para analizar la cuestión de lo que llamaba «pretensión de legitimidad» de los sistemas políticos que, en verdad, era muy similar a la «creencia en la legitimidad» propuesta por Max Weber pero me permitía distinguir entre legitimidad y legitimación. En esta misma línea de pensamiento y con total independencia de fuentes coincidentes, Jesús escribía en 2004:

«Mi gran objetivo [es] enriquecer las discusiones que los iusfilósofos tenemos sobre los derechos humanos (y sobre el Estado social) con los análisis que politólogos, constitucionalistas y economistas han hecho del mismo tema. Si bien estoy convencido de que la filosofía del Derecho ofrece un enfoque sumamente fecundo para el análisis de estos - y otros - temas, estoy igualmente convencido de que, como cualquier otra comunidad académica, los iusfilósofos corremos el riesgo de elaborar un discurso cerrado en sí mismo, inteligible tan sólo para los pertenecientes a dicha comunidad, y que puede perder su inicial potencialidad y fecundidad.» ${ }^{2}$

La observación es correcta: sobre todo a partir del último tercio del siglo XX, la interdiciplinaridad se ha convertido en un rasgo manifiesto de la filosofía y la teoría del derecho. Basta echar una mirada a las investigaciones contemporáneas en este campo para comprobar que tal es el caso.

\section{2}

\section{La autonomía del discurso moral en materia de derechos humanos}

Jesús González AmUCHÁstegui pensaba que una teoría de los derechos humanos sólo podía ser elaborada desde la perspectiva de una moralidad crítica y, por ello, afirmaba:

«El carácter universal de esta moralidad crítica redundará en la universalidad de los derechos proclamados por la misma. Obviamente estos derechos se encuentran fuera del ámbito de los diferentes sistemas jurídico-positivos, pues, efectivamente, no estamos hablando de unos derechos que unos tienen y otros no en función del sistema jurídico en que vivan. [...] creo que es un error negar la universalidad de los derechos humanos argumentando que los derechos humanos de los individuos tienen necesariamente una dimensión estatal...»

\footnotetext{
${ }^{1}$ Cfr. N. P. Barky, An Introduction to Modern Political Theory, Hong Kong 1981, pp. 32 s.

2 J. GonzÁlez Amuchastegui, Autonomía, dignidad y ciudadanía, Valencia, Tirant lo Blanch, 2004, p. 38.

3 Ibidem, p. 319 s.
} 
La adopción de una moral crítica le permitió a Jesús no sólo no caer en las redes de un comunitarismo particularista y tener que «ser tolerante con cualesquiera costumbres o tradiciones» ${ }^{4}$ sino también no sucumbir a la tentación del relativismo axiológico y tener que limitarse a la descripción de los principios y reglas de una moral positiva, es decir, se cuidó muy bien de no confundir punto de vista cultural con punto de vista moral.

3

\section{La relevancia de la constitucionalización de los derechos humanos}

Cito a Jesús:

«lo que más me preocupa en relación con los derechos humanos, es que estén protegidos, que estén garantizados, que sean respetados. Mi objetivo es que los derechos humanos estén recogidos en las Constituciones, sean desarrollados por las leyes y reglamentos, y sean aplicados por los diferentes operadores jurídicos. [...] Igualmente mi objetivo es que el contexto socio-económico favorezca la creación de condiciones para el disfrute real de los derechos humanos. $\rangle^{5}$

La importancia que Jesús otorgaba a la recepción constitucional de los derechos humanos respondía a su convicción de que sólo si eran respetados jurídicamente era también posible el funcionamiento cabal de la democracia. Sabía que «la democracia es el único régimen jurídico-político compatible con las exigencias planteadas por las teorías de los derechos humanos» ${ }^{6}$.

Dicho de otra manera, pienso que Jesús estaría dispuesto a sostener que los derechos humanos constituyen el puente conceptual que vincula dignidad con democracia: la dignidad humana en sociedad sólo puede estar asegurada en una democracia sujeta a restricciones impuestas por el reconocimiento de los derechos humanos. La violación o la falta de vigencia de los derechos humanos afecta los dos pilares del puente: la dignidad se convierte en palabra hueca y la democracia degenera en la tiranía de los demagogos. En el primer caso se animaliza a la persona y en el segundo sucumbimos bajo la avalancha de la voluntad descontrolada de los más o del más fuerte. En ambos casos, la vida individual queda humillada y la vida social se vuelve indecente. Reiteradamente Jesús recordó el papel de los derechos humanos como frenos «no sólo frente a los poderes totalitarios, sino incluso frente a las decisiones mayoritarias» ${ }^{7}$. Consideraba, correctamente en mi opinión, que el respeto a la autonomía individual, a su dignidad en el sentido kantiano de la palabra, es lo que fija «un límite infranqueable incluso para las mayorías» y, con generosidad intelectual, recogía con mención expresa la noción de lo que he llamado «coto vedado» ${ }^{8}$.

$$
* * *
$$

${ }^{4}$ Ibidem, p. 292.

5 Ibidem, p. 42.

${ }^{6}$ Ibidem, p. 468.

7 Ibidem, p. 407.

${ }^{8}$ Ibidem, p. 408. 
A esta altura de mi vida, cuando se me muere un amigo entrañable me siento como sobreviviente en creciente soledad. Sé que es inútil pretender eliminar la tristeza por lo perdido. Sé también que toda explicación de un destino frustrado es empresa vana. Pero también percibo que una de las cosas buenas que a uno pueden pasarle en la vida es contar con el afecto de personas a quienes uno ha querido por buenas razones. $\mathrm{La}$ amistad no es ciega y son las buenas razones las que le confieren un valor que supera lo meramente subjetivo. ¡Y vaya si había buenas razones para sentirse amigo de Jesús!: integridad moral, modestia intelectual, pasión política por la conformación democrática de la realidad social, rechazo de lo fatuo, capacidad para escuchar argumentos y conservar la fidelidad a los principios morales que dan sustento a la defensa de la dignidad propia y ajena. No fue casual que Jesús escribiera un grueso volumen sobre estas cuestiones que eran para él, como solía decir, las que le preocupaban no sólo teórica sino prácticamente. Por ello, estuvo dispuesto a imponerse una pausa en su actividad universitaria para poder dedicarse más activamente a los problemas de la actividad judicial y política. Lo vi por última vez en Barcelona, en diciembre de 2007, en casa de José Luis MARTí. Acababa de concluir un curso de teoría del Derecho en la Universidad Pompeu Fabra invitado por Jorge MALEM. Con no poca desilusión se explayó entonces sobre el destino político de España. Pensaba volver a dedicarse activamente a la Universidad. Unos meses más tarde me comunicaba su fatiga física y la conveniencia de imponerse un descanso. En el XIV Congreso Italo-Español de Teoría del Derecho, (14-15 de noviembre de 2008), cuando acabábamos de idear con José María SAUCA invitarlo a que dictara unas conferencias en la Fundación Coloquio Jurídico Europeo, nos enteramos de su muerte.

Porque Jesús fue la persona cabal que quisimos, pienso que debemos suavizar la tristeza que provoca su muerte con el recuerdo de lo con él compartido y la conciencia de haber sido afortunados por haber podido recorrer con él un trecho de esta extraña e irrepetible experiencia que llamamos vida. Quienes, sin haberlo conocido, lean sus trabajos sacarán el provecho que brinda una obra hecha con pasión intelectual e integridad moral. Todo esto alcanza y sobra para justificar un buen vivir: no es mucho más lo que nos está concedido aquí y ahora. 